\title{
Particulate Matter Pollution in the United Arab Emirates: Elemental Analysis and Phase Identification of Fine Particulate Pollutants
}

\author{
Nasser M. Hamdan ${ }^{1,2}$, Hussain Alawadhi², Najeh Jisrawi ${ }^{2}$ \\ ${ }^{1}$ Physics department, American University of Sharjah \\ Sharjah, United Arab Emirates \\ nhamdan@aus.edu \\ ${ }^{2}$ Centre for Advanced Materials Research, University of Sharjah \\ Sharjah, United Arab Emirates \\ halawadhi@sharjah.ac.ae; njisrawi@sharjah.ac.ae
}

\begin{abstract}
An urban background sampling campaign was performed to measure $\mathrm{PM}_{2.5}$ pollutants in Sharjah, United Arab Emirates. Gravimetric analysis, smoke stain reflectometry, XRF and XRD measurements and analysis were performed on samples collected on 47 $\mathrm{mm}$ Teflon filters following international sampling procedures. The $\mathrm{PM}_{2.5}$ amounts are within WHO limits in the absence of natural dust storms. Elemental composition and phase identification of major pollutants were determined. In the absence of dust storms, fossil fuel burning originating from traffic and energy generation are the major sources of $\mathrm{PM}_{2.5}$ in the form of secondary phases formed from gaseous precursors. Primary pollutants such as quartz, calcite and gypsum and sea salts are the main pollutants during dusty days. Natural sources such as sea salts and crustal materials also contribute to $\mathrm{PM}_{2.5}$ both as primary sources and through interaction with anthropogenic emissions to form new secondary phases depending on factors such as the ambient conditions and primary pollutants. Integration of different techniques provided us with a better understanding of sources of pollutants and their interaction during their transport in the atmosphere. Reduction of major secondary pollutants in $\mathrm{PM}_{2.5}$ has already been observed through various clean energy initiatives in the country and by implementing green building codes and enforcing strict regulations on industrial emissions.
\end{abstract}

Keywords: Aerosol, $\mathrm{PM}_{2.5}$, Air pollution, XRD, XRF anthropogenic emissions, dust storms, UAE

\section{Introduction}

The World Health Organization (WHO) reported that 7 million annual deaths in 2012 were directly linked to air pollution, one eighth of the total global deaths $[1,2]$, with 2.6 million deaths related to outdoor air pollution. Recently, C.M. Wong et al.[3] have recruited more than 66,000 persons from Hong Kong, all above the age of 65 years in 1988 to 2001 and followed up for mortality outcomes until 2011. They have found that $\mathrm{PM}_{2.5}$ was associated with increased risk of mortality for all causes of cancer including cancer in upper digestive tract, digestive accessory organs, breast cancer in females and lung cancer in males. They reported that for every 10 microgram per cubic meter $\left(\mu \mathrm{g} / \mathrm{m}^{3}\right)$ of increased exposure to $\mathrm{PM}_{2.5}$, the risk of dying from any cancer rose by 22 percent.

Y. Li et al. have published the first detailed study on health consequences of air pollution in the UAE [4]. They attributed about 545 deaths only in 2007 in the UAE to particulate matter pollutants. Despite uncertainty in the PM background levels in the UAE due to frequent dust storms, they concluded that anthropogenic pollutants are a considerable public health risk in terms of premature death. Nevertheless, their study did not investigate size-resolved elemental distribution. The study used $\mathrm{PM}_{10}$ data from Abu Dhabi only and interpolated ambient concentrations at locations and times for which monitored concentrations are unavailable.

Bener et al. [5] reported the number of hospital admission for air pollution related diseases in Qatar in the period (2002-2005) and the average levels of air pollutants during the same period. Correlations between air pollutant levels and hospital admission for respiratory, cardiovascular and Ischemic heart diseases were observed for the study period. They also reported a systematic annual increase in the $\mathrm{PM}_{10}$ levels between 2002 and 2005. They recommended immediate investigation and monitoring of PM matter to be conducted. 
$\mathrm{PM}_{2.5}$ are potentially of greater concern for human health because these smaller particles can penetrate more deeply into the lungs and thus cause extensive damage. They may also get into the blood stream causing serious diseases such as cancer and cardiovascular disease [4-6]. Sand storms also contribute to an increase in the concentration of $\mathrm{PM}_{2.5}$ [4,7]. Outdoor air pollution in the UAE was identified by a national strategy action plan [8] to be the number one environmental health hazard in the UAE and indoor air pollutants to be the number two environmental health hazard among fourteen other environmental health hazards. Poor air quality is apparent from ambient measurements and degraded visibility [8,9]. There have been only a few studies [4-14] documenting the existence of large amounts of air pollutants in the UAE (mainly PM PM $_{10}$ and $\mathrm{PM}_{2.5}$ ).

The East Mediterranean and North African regions are among the regions that are highly susceptible to air pollution because of the weather as it is considered to be an arid region, the existence of large desert regions and the unprecedented development that the region is going through. In addition, there is lack of studies and data on both air pollution (size distribution, elemental and chemical composition and source apportionment) and on their health effects [4 - 14]. The UAE and the region in general experience regular dust and sand storms that contribute to the amount of particulate matter pollutants $(\mathrm{PM})$ in air. These storms contribute both to the coarse fraction of $\mathrm{PM}_{10}$ (particulates with aerodynamic diameter between 10 $\mu \mathrm{m}$ and $2.5 \mu \mathrm{m})$ and to the fine and ultrafine fraction $\left(\mathrm{PM}_{2.5}\right)$. Other natural sources of pollution such as sea salts originating from sea breeze and crustal materials also contribute both to coarse and fine fractions of PM. On the other hand, the Gulf region including the United Arab Emirates (UAE) are quickly developing with mega construction projects, a huge oil industry, water desalination projects, and congested traffic; all of which result in a large increase of anthropogenic pollutants. Anthropogenic emissions mainly contribute to the fine and the ultrafine fractions of PM. Emissions originating directly from these sources are known as primary pollutants. Furthermore, natural and anthropogenic primary pollutants interact during transport to form new phases of the so-called "secondary pollutants". For example, $\mathrm{SO}_{2}$ and $\mathrm{NO}_{\mathrm{x}}$ are main emissions of fossil fuel burning that interact with oxygen and humidity to form nitrates and sulphates with particulates of very fine sizes. A number of new phases may be formed as a result of interaction of quartz (from desert sand) and calcite (from building material) with sea salts and $\mathrm{SO}_{2}[15]$.

Among the factors that contribute to the severity of air pollution and particularly PM pollution in the UAE is that it is considered arid country with average annual rain fall of less than $12 \mathrm{~cm}$, and the none-existence of forests, where PM especially $\mathrm{PM}_{2.5}$ remain suspended in the atmosphere for prolonged times. Because of the high levels of humidity in the country, some pollutants are still hydrolyzed or partially hydrolyzed despite having low rain fall levels. The interaction of natural and anthropogenic emissions and the existence of humidity could lead to modification of toxicity of coarse and fine aerosol [15-16]. Engelbrecht et.al [17], have conducted a study for the US Department of Defence on the chemical and physical properties of dust collected from five deployment locations at 15 military sites in the Middle East including Iraq, Kuwait, Afghanistan, Qatar and UAE. Although their study is one of the major works performed in this field in the region, it still needs follow up and complementary investigations. The study investigated samples collected only from one site in Qatar and one in the UAE. These two sites were at military bases in the desert far from urban residential areas in both countries. Urban and residential areas are more susceptible to industrial and traffic pollution. Furthermore, the study was conducted over a period of one year in 2006-2007, more than 8 years ago. Great development in the region especially in the UAE took place during the last 8 years. An important result of Engelbrecht's et.al [17] study is that $\mathrm{PM}_{10}$ and $\mathrm{PM}_{2.5}$ levels are considerably higher than the accepted standards (three to four times higher). This result requires a follow-up and the expansion to residential and industrial areas in order to come up with understanding the chemistry of PM during their transport in the atmosphere which has direct impact on human health and try to attribute these pollutants to their sources and come up with an effective monitoring strategy.

In a recent preliminary study, we found in that a major fraction of the $\mathrm{PM}_{2.5}$ pollutants including the very fine fraction (less than $0.5 \mu \mathrm{m}$ ) is ammonium sulphate for samples collected from both indoors and outdoors. The outdoor results were found in samples collected from an urban background site. We believe that urban areas may have different chemical and size distribution of pollutants, due to interaction of pollutants from various anthropogenic sources and natural sources [15]. We have also conducted a preliminary study on the size and elemental distribution of PM in two major UAE cities: Dubai and, Sharjah [18-20]. We used double-stage samplers, the total suspended particles (TSP) and the multistage impactor in these studies. In this work, we have performed a comprehensive sampling campaign to collect $\mathrm{PM}_{2.5}$ from an urban background site in Sharjah. The project involved gravimetric measurements, elemental distribution and chemical analysis of the constituents of $\mathrm{PM}_{2.5}$. 


\section{Experimental}

Sampling was performed using a low volume double stage sampling station (IASP-1050e model) [21]. The coarse fraction of $\mathrm{PM}_{10}$ was collected on a $30 \mathrm{~mm}$ inner diameter ring filter, while the $\mathrm{PM}_{2.5}$ collected on $47 \mathrm{~mm}$ Teflon filters. PM Samples were collected for 24 hours every sixth day, using the EN standard (EN12341 $\left.2.3 \mathrm{~m}^{3} / \mathrm{h}\right)$ [21]. Samples were performed between October 15, 2014 and May 1, 2016. The sampling site was carefully chosen to represent an urban background site. The site is located at the roof of the American University of Sharjah Main building, a secured site far enough from any direct pollution source, and the sampler was away from any obstacle. Only $\mathrm{PM}_{2.5}$ results performed on 30 samples will be presented in this article.

Teflon filters were preconditioned and weighed 4 times before (initial) and after (final) sampling according to a standard procedure using a Sartorius CP model microbalance with precision better than $1 \mu \mathrm{m}$. The mass density was calculated using the formula:

$$
M=\frac{\mathrm{Wf}-\mathrm{Wi}}{\mathrm{Q} \times \mathrm{t}}
$$

Where $M$ is the average mass concentration of $\mathrm{PM}_{2.5}$ in air $\left(\mu \mathrm{g} / \mathrm{m}^{3}\right) ; W f$ and $W i$ are the final and initial average mass of the Teflon filter $(\mu \mathrm{g})$, Q is the air flow rate in the sampler $\left(\mathrm{m}^{3} / \mathrm{h}\right)$ and $t$ is the sampling time $(h)$.

Smoke stain measurements were perfumed using an EEL 43M model Smoke-stain Reflectometer, the reflectometer was calibrated before every measurements using two reference samples provided by the manufacturer.

$X$-ray fluorescence (XRF) measurements were performed on Horiba XGT7200, $\mu$-XRF system using the $1.2 \mathrm{~mm}$ beam size, $1 \mathrm{~mA}$ emission current and $50 \mathrm{kV}$ excitation potential. Data were collected for $600 \mathrm{~s}$ on three different spots for each Teflon filter. Semi-quantitative analysis was performed to determine the elemental compositions of the samples which gives the mass percentage content of various elements normalized to the total measured inorganic elements.

X-ray diffraction measurements (XRD) were performed using a Bruker D8 ADVANCE powder XRD, $(2.2 \mathrm{~kW} \mathrm{Cu}$ tube,) and a linear detector. All pattern analysis was performed with a step size of 0.02 degrees and the $2 \theta$ range was between 5 to 55 degrees. The time per step was $0.6 \mathrm{~s}$

\section{Results and Discussions}

The colour of collected PM on Teflon filter varied from dark black to yellow depending on the amount of natural versus anthropogenic pollutants. On clear days with absence of dust storms, samples looked very dark while they tend to have different grey shades on other days. This is directly related to the amount of black (elemental) carbon and anthropogenic emissions in the atmosphere. Figure 1 shows images of three samples with different colours. It is to be noted that the yellow sample identified as sample 47 was collected during a significant sand storm. Smoke stain reflectometry were performed on all samples showing variation of reflectance ranging from 8\% (for sample 65 collected on March 8, 2016) to more than 40\% (for the yellow sample No. 47) that was collected on Saturday February 21, 2015, when we have experienced a severe dust storm. The reflectivity results highly correlate with XRF and XRD results below.

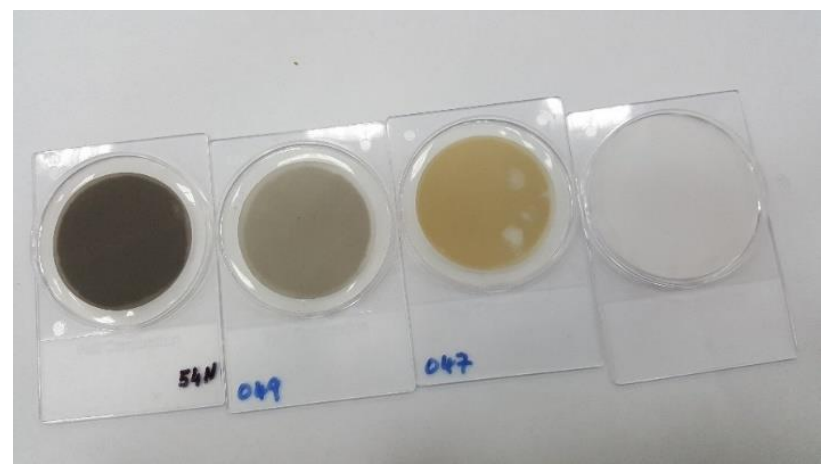

Fig. 1: images for three samples showing the variation of color due to different sources of pollutants.

Gravimetric analysis showed that the amounts of $\mathrm{PM}_{2.5}$ pollutants collected from urban background site are within the WHO limits for more than $40 \%$ of sampling days (even much lower on several days). They were slightly higher (within 
about $10 \%-20 \%$ ) than the internationally accepted limits in about $30 \%$ of the sampling days. Only when there were a dust storms, numbers increased and may reach about twice the accepted limits. Natural pollutants originating form dust storm and sea salts also contribute to the amount of $\mathrm{PM}_{2.5}$ in the atmosphere.

XRF spectra for all samples were performed using Horiba XGT7200 system as explained above. Typical XRF scans are shown in Fig.1 and Fig. 2. The scan parameters are shown on the figures.

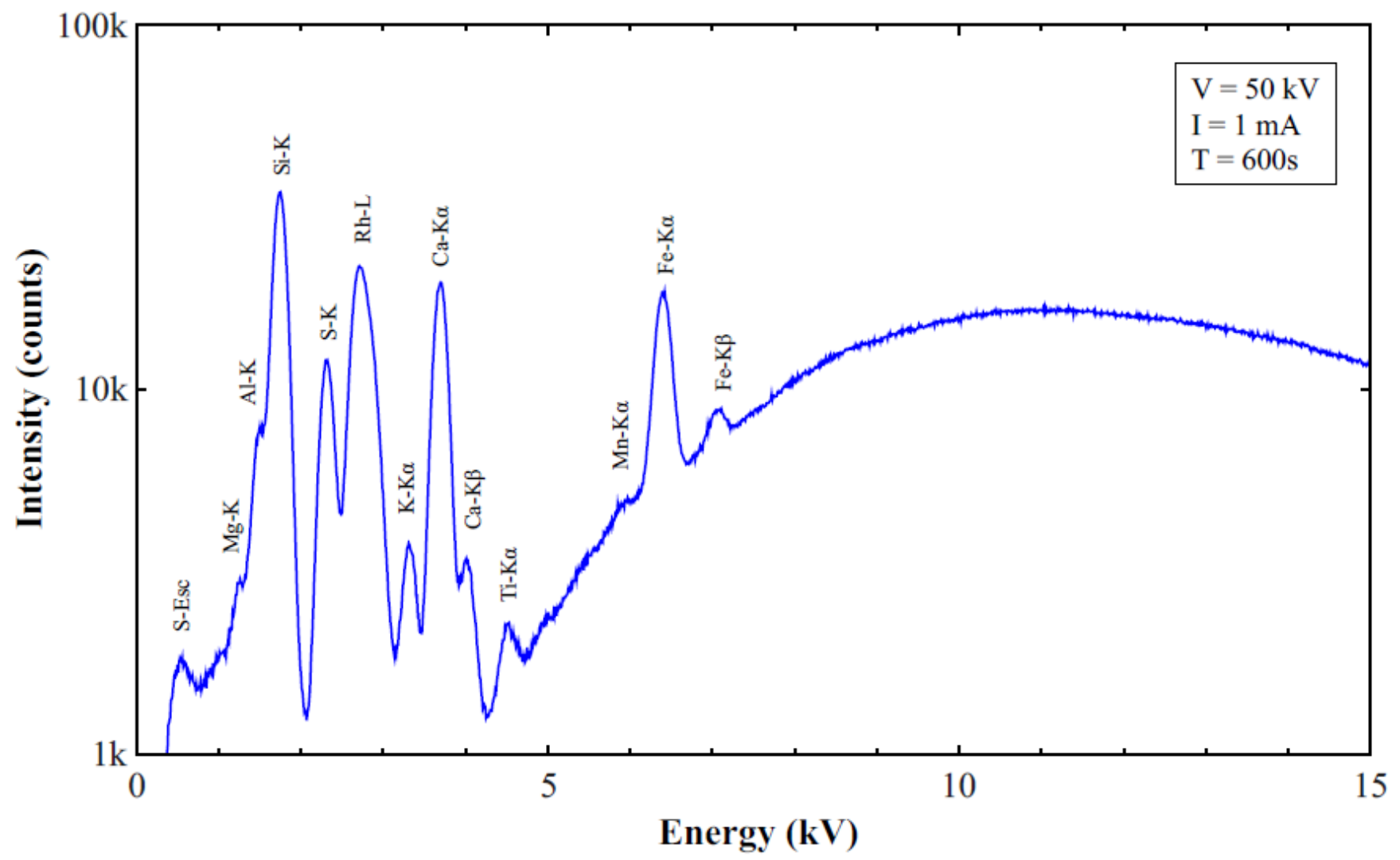

Fig. 2: XRF spectra for Filter No 31, showing that $\mathrm{Si}$, $\mathrm{Ca}$ and $\mathrm{Fe}$ are the dominant elements.

Fig. 2 for sample 31, shows that pollutants originating from natural sources are dominenat. These elements are $\mathrm{Si}$, Ca, $\mathrm{Fe}, \mathrm{Al}$, and $\mathrm{Ti}$, while $\mathrm{S}$ is a minor element as shown from the logarithmic scale. These results are consistent with garvemitric results where the amount of $\mathrm{PM}_{2.5}$ on that day was among the highest (about $63 \mu \mathrm{g} / \mathrm{m}^{3}$ ). This sample was collectd on Saturday November 11, 2014 where we have experienced a dust storm on that day. XRD analysis below will also suport these results. These results indicate that the detected pollutants are mainly due to natural sources (Quartz originating from the desert) and crustal material and sea salts.

Table 1 below shows the mass perecentages of major elements detected by a semi-quatitative analysis of different PM samples collected on Teflon filters. Zero percenatge means that the value was beow the detection limit. This is due to the fact that no x-ray filters were used in these scans. Careful investigation of the numbers in the table shows that there is a strong corrolation between elemnts originating form natural sources such as dust storms, buiding materials and crustal materials. Table 2, shows the corrolations between various elements. The elements that have high corrolation(in bold) are $\mathrm{Si}, \mathrm{Ca}, \mathrm{Fe}$, Ti, while ther is a very strong negative corrolation beween these elements and $\mathrm{S}$ and $\mathrm{Zn}$ (bold shaded), while $\mathrm{S}$ and $\mathrm{Zn}$ has showed positive corrolation. These reults suggest that anthorpgenic pollutants such as $\mathrm{S}$ and $\mathrm{Z}$, dominate in clear days and in the absent of dust event, and the main consitituent of the XRF spectra of fine and ultrafine fractions of $\mathrm{PM}_{10}$ is $\mathrm{S}$. As mentioned above, this suggests that traffic is a major source of pollutants. Fossil fuel burning emits $\mathrm{SO}_{2}$, that become a precursor for fine and ultrafine PM in the form ammonium sulphate. These results will be confirmed later in the article when we dicuss XRD results. The corrolation between $\mathrm{Zn}$ and $\mathrm{S}$ suggest that they are originating from sources. Zinc is known to be a constituent of tires and motor oil additives [23]) and emission and industrial processing [24]). 


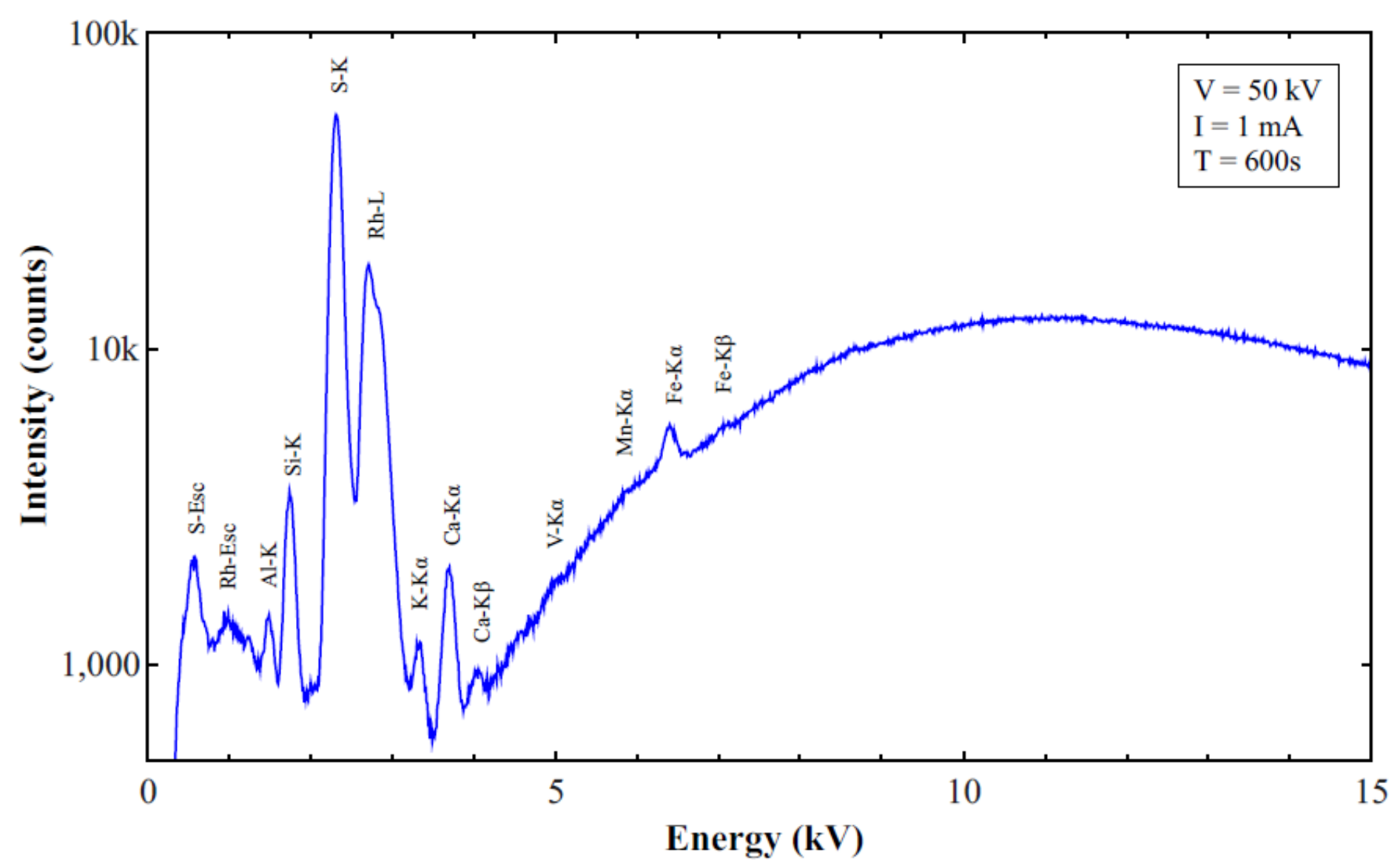

Fig. 3: XRF spectra for Filter No 40, showing that $\mathrm{S}$ is the dominant elements. Please note the logarthmic scale.

Figure 4 shows the XRD pattern for sample 40. The peaks marked with (M) belong to ammonium sulfate phase known as Mascagnite. Other phases present are Calcite Magnesian ( $\mathrm{Ca}, \mathrm{Mg}) \mathrm{CO}_{3}$ marked with (GL) and IIlittle 2M2, glycolated $\left(\mathrm{K}, \mathrm{H}_{30}\right) \mathrm{Al}_{2}\left(\mathrm{Si}_{3} \mathrm{AL}\right) \mathrm{O}_{10}(\mathrm{OH})_{2} \mathrm{X} \mathrm{H} \mathrm{H}_{2} \mathrm{O}$. It is abvious that the main phases in this sample are secondary phases that have been formed during trasport of primary gaseous precursors such as $\mathrm{SO}_{2}$ togther with other natural and anthropogenic emissions. For exampe the sulfer dioxide a major gas emission from vehicles and enrgy power plants follows the following reaction route:

$$
\begin{aligned}
& \mathrm{SO}_{2}+1 / 2 \mathrm{O}_{2} \rightleftarrows \mathrm{SO}_{3} \\
& \mathrm{SO}_{3}++\mathrm{H}_{2} \mathrm{O} \rightleftarrows \mathrm{H}_{2} \mathrm{SO}_{4} \\
& 2 \mathrm{NH}_{3}+\mathrm{H}_{2} \mathrm{SO}_{4} \leftrightarrow\left(\mathrm{NH}_{4}\right)_{2} \mathrm{SO}_{4} \quad \text { (aqueous/solid) }
\end{aligned}
$$

Thereofre $\mathrm{SO}_{2}$ gas ends up in the atmophere eitehr as an acid (causing acid rain) or as ammonium sulphate that exisists in the ultra fine range [Hamdan]. Therefore, chemical speciation of PM is very essential to undestand the reaction and interaction mechanisms of primary natural and anthropogenic pollutants during their tranport to produce various secondary pahses that may have modified toxicity.

Fig. 5 represents the XRD pattern for sample 47 that consists mainly of natural pollutants originated from a sever dust storm. The two main phases in this sample are calcite and gypsum, in addition to few secondary phases (such as the phase marked as Y: known as Yofortierite). The main compounds (C and $\mathrm{G})$ are primary pollutants carried with the winds to urban areas. Unlike the case of sample 40 above, the $\mathrm{S}$ in this sample is mainly due to gypsum rather than ammonium sulphate that originates from anthropogenic emissions. This may not indicate that there are no anthropogenic emissions, but the weather conditions may have not been suitable for the formation of ammonium sulphates from sulphur dioxide. It may also indicate that because of the high concentration of natural emissions, calcite and gypsum exist in very large amounts and therefore other pollutants are not detected. 
Table 1: Mass percantges of major pollutants in several $\mathrm{PM}_{2.5}$ samples normalized to the toal measured inorganic elements.

\begin{tabular}{|c|c|c|c|c|c|c|c|c|c|c|c|c|}
\hline filter No & $\mathrm{Mg}$ & AL & $\mathrm{Si}$ & $s$ & $\mathbf{K}$ & $\mathrm{Ca}$ & $\mathrm{Ti}$ & v & Mn & $\mathrm{Fe}$ & $\mathrm{Zn}$ & $\mathrm{Pb}$ \\
\hline 26 & 0 & 0 & 49.38 & 31.55 & 2.69 & 12.74 & 0.42 & 0.12 & 0.09 & 2.96 & 0.05 & 0 \\
\hline 27 & 9.01 & 9.52 & 27.76 & 46.49 & 0 & 5.71 & 0.18 & 0 & 0.07 & 1.13 & 0.11 & 0 \\
\hline 28 & 7.75 & 7.95 & 26.335 & 49.385 & 1.56 & $6 . .41$ & 0.17 & 0.06 & 0.045 & 1.105 & 0.035 & \\
\hline 29 & 0 & 0 & 30.35 & 44.03 & 2.34 & 20.6 & 0.36 & 0 & 0.07 & 2.04 & 0.09 & 0.05 \\
\hline 31 & 0 & 0 & 56.6 & 13.52 & 3.75 & 17.41 & 0.59 & 0.12 & 0.11 & 3.4 & 0.03 & 0 \\
\hline 32 & 10.39 & 8.84 & 34.46 & 35.97 & 0 & 8.75 & 0.16 & 0 & 0 & 1.37 & 0.06 & 0 \\
\hline 33 & 5 & 4.92 & 12.64 & 75.18 & 1.59 & 5.17 & 0.17 & 0.02 & 0.075 & 0.885 & 0.1 & \\
\hline 34 & 11.68 & 5.56 & 20.215 & 57.005 & & 12.05 & 0.245 & & 0.13 & 1.59 & 0.205 & \\
\hline 35 & 0 & 0 & 4.61 & 87.11 & 0 & 0 & 0 & 0 & 0 & 0.73 & 0.59 & 0 \\
\hline 36 & 12.875 & 10.75 & 41.515 & 22.59 & 1.33 & 9.88 & 0.18 & 0.03 & 0.06 & 1.39 & 0.04 & \\
\hline 37 & 13.37 & 10.12 & 38.22 & 20.81 & 1.43 & 13.79 & 0 & 0 & 0 & 1.73 & 0 & 0.2 \\
\hline 38 & 7.2 & 5.2 & 14 & 66 & 1.7 & 5.4 & 0.1 & 0.1 & 0.1 & 0.9 & 0 & 0 \\
\hline 39 & 7.12 & 4.485 & 13.395 & 64.815 & 2.77 & 6.3 & 0.12 & 0.06 & 0.115 & 0.82 & 0.03 & 0.02 \\
\hline 40 & 4.42 & 3.9 & 8.4 & 77.9 & 1.9 & 2.92 & 0 & 0.115 & 0 & 0.63 & 0.05 & 0 \\
\hline 41 & 5.09 & 3.86 & 10.3 & 73.37 & 1.6 & 4.51 & 0.125 & 0.08 & 0.085 & 0.865 & 0.09 & 0.03 \\
\hline 42 & 8.84 & 11.36 & 33.33 & 37.145 & 1.77 & 5.75 & 0.225 & & 0.06 & 1.3 & 0.245 & \\
\hline 48 & 4.33 & 3.505 & 12.25 & 69.885 & 1.385 & 3.45 & 0.13 & 0.06 & 0.09 & 0.83 & 0.07 & \\
\hline 43 & 8.35 & 5.93 & 12.7 & 58.9 & 3.32 & 8.41 & 3.99 & 0.08 & 0.247 & 1.28 & 0.113 & \\
\hline 44 & 7.11 & 5.35 & 14.57 & 59.66 & 1.39 & 6.37 & 0.15 & 0.07 & 0.07 & 0.81 & 0.08 & \\
\hline 45 & 9.275 & 6.75 & 21.705 & 46.56 & 1.34 & 8.78 & 0.125 & 0.01 & 0.03 & 1.025 & 0.025 & \\
\hline 46 & 10.31 & 14.98 & 45.345 & 16.96 & 1.65 & 8.855 & 0.31 & 0.015 & 0.065 & 1.465 & 0.025 & \\
\hline 47 & 9.605 & 12.21 & 43.29 & 8.41 & 1.45 & 20.07 & 0.405 & & 0.055 & 2.265 & 0.01 & \\
\hline \multicolumn{13}{|l|}{49} \\
\hline 50 & 8.19 & 6 & 15.1 & 45.7 & 1.67 & 4.56 & 0.09 & 0.045 & 0.03 & 0.49 & 0.015 & 0.01 \\
\hline 51 & 7.48 & 10.04 & 31.48 & 42.56 & 1.52 & 5.19 & 0.235 & 0.06 & 0.065 & 1.305 & 0.02 & \\
\hline 52 & 9.955 & 12.75 & 41.45 & 23.53 & 1.76 & 8.575 & 0.285 & 0.03 & 0.07 & 1.525 & 0.04 & \\
\hline 53 & 10.635 & 10.095 & 35.49 & 27.675 & 1.524 & 9.31 & 0.21 & 0.03 & 0.04 & 1.175 & 0.015 & \\
\hline 54 & 4.76 & 6.12 & 17.83 & 64.5 & 1.29 & 4.06 & 0.13 & 0.05 & 0.06 & 0.91 & 0.04 & \\
\hline 55 & 10.135 & 11.44 & 44.32 & 18.72 & 1.47 & 11.635 & 0.305 & 0.03 & 0.05 & 1.845 & 0.01 & 0.01 \\
\hline 56 & 6.735 & 5.775 & 24.435 & 53.04 & 1.55 & 7.21 & 0.155 & 0.03 & 0.035 & 1.015 & 0.02 & \\
\hline 57 & 9.015 & 11.18 & 40.015 & 29.225 & 1.87 & 7 & 0.225 & 0.035 & 0.04 & 1.34 & 0.02 & \\
\hline
\end{tabular}

Table 2: Corrolation table between various elements.

\begin{tabular}{|c|c|c|c|c|c|c|c|c|c|c|c|c|}
\hline & $\mathrm{Mg}$ & AL & $\mathrm{Si}$ & $\mathrm{s}$ & $\mathrm{K}$ & $\mathrm{Ca}$ & $\mathrm{Ti}$ & $\mathrm{V}$ & $\mathrm{Cr}$ & $\mathrm{Mn}$ & $\mathrm{Fe}$ & $\mathrm{Zn}$ \\
\hline $\mathrm{Mg}$ & 1 & 0.840639 & 0.351315 & -0.41613 & -0.29856 & 0.036271 & 0.013519 & -0.41688 & -0.02471 & -0.08601 & -0.20867 & -0.33457 \\
\hline AL & & 1 & 0.572476 & -0.57976 & -0.29612 & 0.039889 & -0.04389 & -0.43386 & 0.097047 & -0.18941 & -0.0849 & -0.33435 \\
\hline $\mathrm{Si}$ & & & 1 & -0.95649 & 0.154732 & 0.665984 & \begin{tabular}{|l|}
-0.06694 \\
\end{tabular} & -0.20814 & 0.223368 & -0.13603 & 0.79757 & -0.38191 \\
\hline$S$ & & & & 1 & -0.17059 & -0.69414 & -0.00256 & 0.174069 & -0.25872 & 0.108988 & -0.68565 & 0.454209 \\
\hline $\mathrm{K}$ & & & & & 1 & 0.398971 & 0.478455 & 0.637503 & 0.114393 & 0.641494 & 0.472099 & -0.34436 \\
\hline $\mathrm{Ca}$ & & & & & & 1 & 0.131155 & -0.04836 & 0.528817 & 0.13546 & 0.817806 & -0.33396 \\
\hline $\mathrm{Ti}$ & & & & & & & $\begin{array}{l}1 \\
\end{array}$ & 0.217919 & 0.311745 & 0.763593 & 0.142005 & 0.020535 \\
\hline $\mathrm{V}$ & & & & & & & & 1 & -0.39449 & 0.439901 & 0.233266 & -0.23684 \\
\hline $\mathrm{Cr}$ & & & & & & & & & 1 & 0.029703 & 0.128735 & -0.14917 \\
\hline $\mathrm{Mn}$ & & & & & & & & & & 1 & 0.191572 & -0.04668 \\
\hline $\mathrm{Fe}$ & & & & & & & & & & & 1 & -0.1797 \\
\hline$Z n$ & & & & & & & & & & & & 1 \\
\hline
\end{tabular}




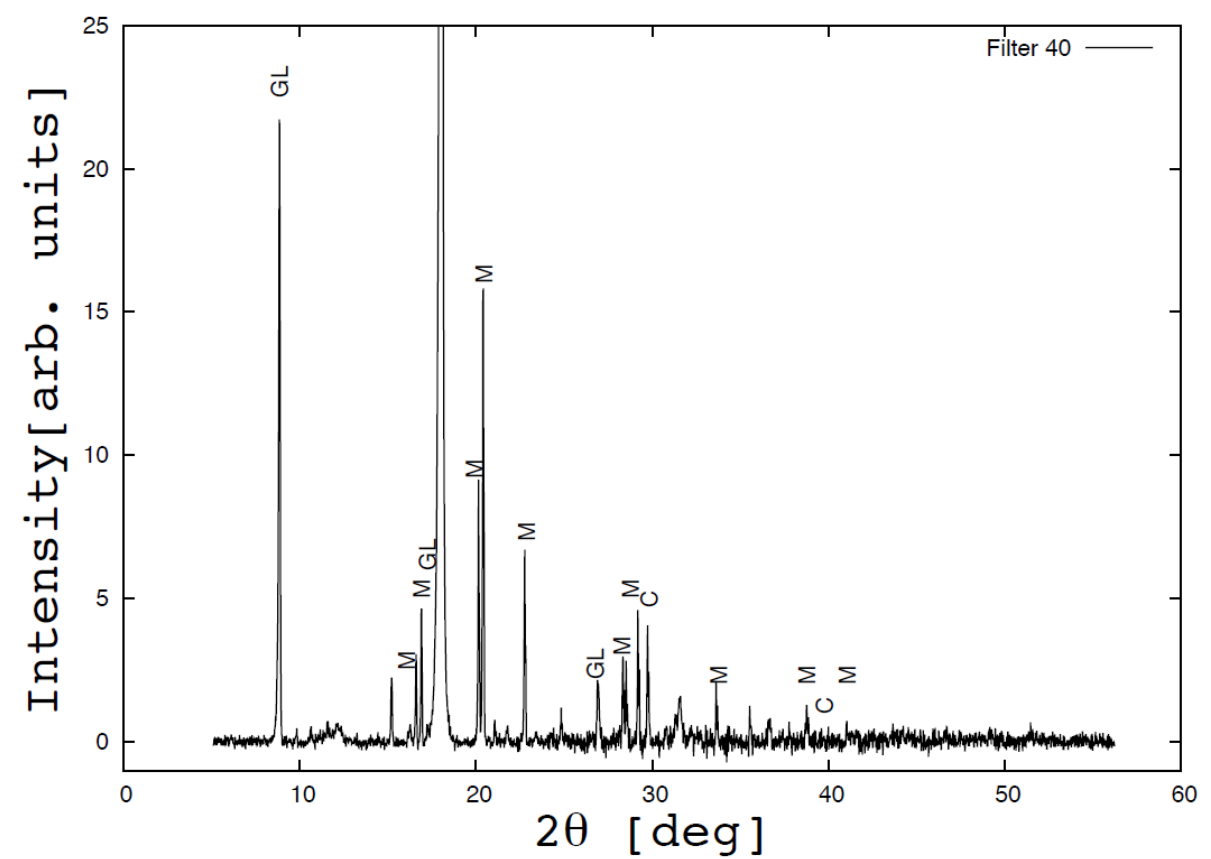

Fig. 4: XRD pattern for Filter No 40: the man phase (M) is identified for Mascagnite $\left(\mathrm{NH}_{4}\right)_{2} \mathrm{SO}_{4}$, and phase (C) is identified as Calcite Magnesian $(\mathrm{Ca}, \mathrm{Mg}) \mathrm{CO}_{3}$.

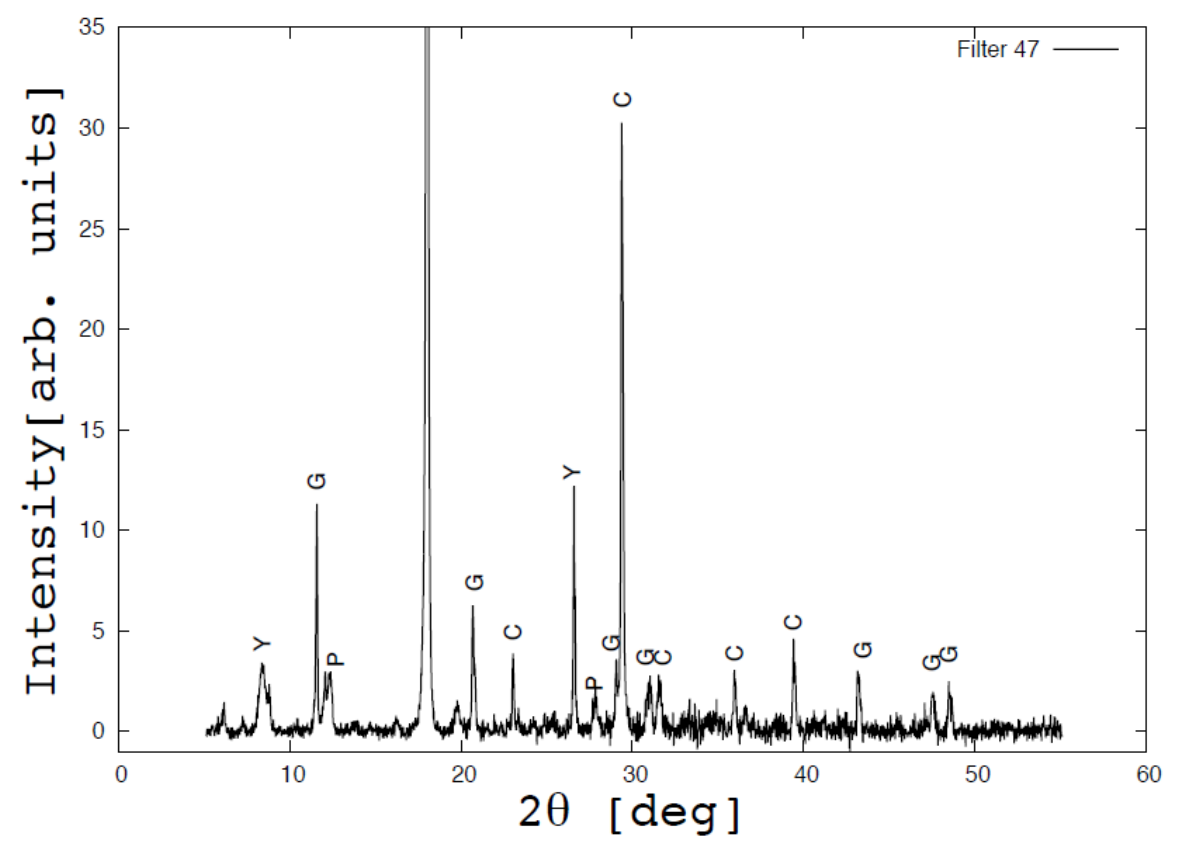

Fig. 5: XRD pattern for Filter No 47: the main two phases are (C) is identified for Calcite (CaCO3) and (G) is identified Gypsum $\mathrm{CaSO}_{4} \cdot 2 \mathrm{H}_{2} \mathrm{O}$. The peak with maximum intensity is resulting from the blank filter.

Fig. 6 shows the XRD patten of sample 31. As is the case for sample 47 above, natural pollutants are dominant in this sample. Neverthelss, and unlike sample 47, this sample has quartz as one of the major consituiuets, in addition to calcite and gypsum. Quartz originates from large desert areas that suround major cities in the UAE including the sampling site in Sharjah. The presence of other secndary phases such as the phase marked as S (Cronstendtite 1-M) which has the chemical formula: $\mathrm{Fe}_{3}(\mathrm{Si}, \mathrm{Fe})_{2} \mathrm{O}_{5}(\mathrm{OH})_{4}$ confirms that the formation of secondary phases is a complex process that depends on several factors such as the ambient temperature, the humidity and the presence of various primary pollutants both of natural and 
anthropogenic emissions. XRD results agree with the findings of the XRF results above. Because of the strong corrolation between natural pollutants and the strong negative corrolation between sulphur and primary natuarl emissions, it is difficut to identify variuos anthrpogenic pollution sources during dust events. The results also show the need to carry out a more extensive investigation with quantitaive analysis for $\mathrm{PM}_{2.5}$ in the region in order to understand the reaction mechanism of polltants and identify pollotion sources. Such extensive study has already statred in our lab utilizing a Theromo Scentific ARL Quant'x analyzer with $9 \mathrm{~mm}$ beam size to provide a more reliable avarage resukts and using various $\mathrm{x}$-ray filters and thin film standards.

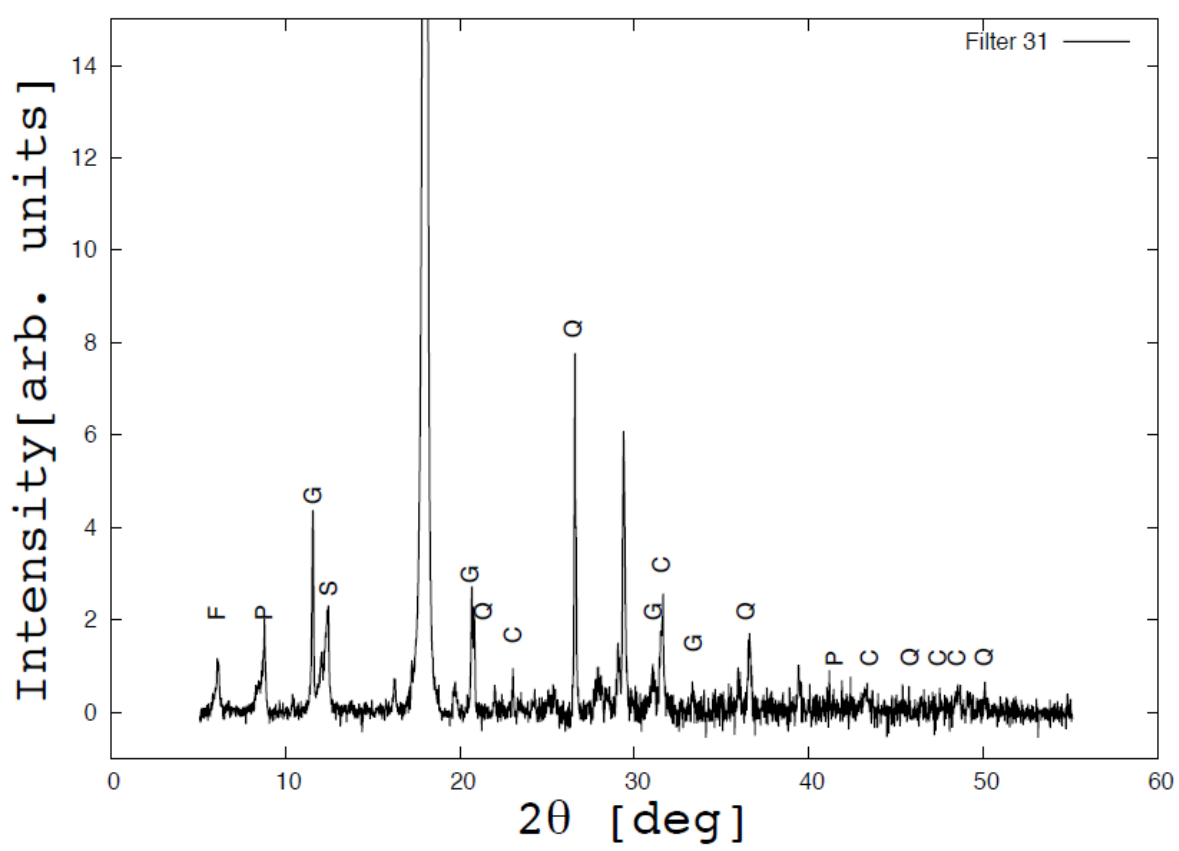

Fig. 6: XRD pattern for Filter No 31: the main phases are Quartz (Q) $\mathrm{SiO}_{2}$. (C) is identified for Calcite (CaCO3) and (G) is identified Gypsum $\mathrm{CaSO}_{4} \cdot 2 \mathrm{H}_{2} \mathrm{O}$. The peak with maximum intensity is resulting from the blank filter.

\section{Conclusion}

This work has shown that pollution sources in the UAE vary between natural and anthropogenic. We have also found that in the absence of dust storms events, the amount of $\mathrm{PM}_{2.5}$ are within international standards as found from gravimetric measurements. We have also noticed that secondary pollutants originating from interaction of various primary sources including gaseous precursors such as $\mathrm{SO}_{2}$ and $\mathrm{NO}_{\mathrm{x}}$, are the major constituents of $\mathrm{PM}_{2.5}$ especially in clear days. The formation of large amounts of ammonium sulphate suggests that fossil fuel burning is the major source of anthropogenic emission. The country has taken practical steps to remediate or decrease these emissions by the move towards nuclear power generation, various solar energy projects and modern public transportation systems. In addition, the country is implementing strict regulations and codes for all industries to monitor and control their emissions. This has significantly contributed to the reduction of anthropogenic emissions from their sources. High standards annual vehicle inspections will also significantly reduce the emissions of various pollutants such as $\mathrm{Zn}, \mathrm{Cu}$ and $\mathrm{Fe}$ (Fe has both natural and anthropogenic sources). As for natural sources, modern highways and street projects in the country have reduced the resuspension of dust, large areas of vegetation and green areas around urban environment will considerably trap natural dust and pollutants. Further detailed quantitative determination of various elements, chemical speciation followed by source apportionment study has just started in order to better understand pollution sources in the country and the region.

\section{Acknowledgements}

$\mathrm{NH}$ acknowledges the support of AUS through FRG grants. He also acknowledges the support of IAEA in Vienna through RAS0072 and RAS0076 projects. 


\section{References}

[1] WHO. (2014). "Seven million premature deaths annually linked to air pollution," [Online]. Available: http://www.who.int/mediacentre/news/releases/2014/air-pollution/en/

[2] WHO. "Burden of disease from ambient and household air pollution," [Online]. Available: http://www.who.int/phe/health_topics/outdoorair/databases/en/

[3] C. M. Wong, H. Tsang, H. K. Lai, G. N. Thomas, K. B. Lam, K. P. Chan, Q. Zheng, J. G. Ayres, S. Y. Lee, T. H. Lam, and T. Q. Thach, "Cancer Epidemiology, Biomarkers \& Prevention," 2016.

[4] Y. Li, et al, "Science of the Total Environment," vol. 408, pp. 5784-5793, 2010.

[5] A. Bener, M. Dogan, M. S. Ehlayel, N. J. Shanks, and A. Sabbah, Eur Ann Allergy Clin Immunol, vol. 41, no. 3, pp. 8084, 2009.

[6] A. Heather, H. et al. Atmospheric Environment, vol. 45, pp. 1444e1453, 2011.

[7] Science Plan, "United Arab Emirates Unified Aerosol Experiment (UAE)," DWRS, NASA, NRL, ONR, 2004.

[8] The National Strategy and Action Plan for Environmental Health for the UAE, Abu Dhabi, 2010.

[9] Air Quality and Atmospheric Pollution, "In the Arab Region, United Nations Environment Programme, Regional Office for West Asia," 2009.

[10] K. A. Miller, D. S. Siscovick et al., "Long-Term Exposure to Air Pollution and Incidence of Cardiovascular Events in Women," New England Journal of Medicine, 2007.

[11] E. Al Katheeri, F. Al Jallad, and M. Al Omar, Journal of Environmental Protection, vol. 3, pp. 640-647, 2012.

[12] V. Tsiouri, K. E. Kakosimos, and P. Kumar, Air Qual Atmos Health, vol. 8, pp. 67-80, 2015.

[13] K. Yeatts et al., Environmental Health Perspectives, vol. 120, pp. 632-636, 2012.

[14] M. Gibson, J. Thomsen, F. Launay, E. Harder, and N. DeFelice, "Deaths and Medical Visits Attributable to Environmental Pollution in the United Arab Emirates," PLoS ONE, vol. 8, no. 3, pp. e57536, 2013.

[15] K. E. Ross, S. J. Piketh, J. S. Reid, and E. A. Reid, “American Geophysical Union,” 2012.

[16] N. M. Hamdan, H. Al-Awadhi, and N. Jisrawi, "Elemental and Chemical Analysis of PM10 and PM2.5 Indoor and Outdoor Pollutants in the UAE," International Journal of Environmental Science and Development, vol. 6, no. 8, pp. 566-570, 2015.

[17] E. Terradellas. (2015, Dec. 14). Presentations. [Online]. Available: http://sds-was.aemet.es/materials/workshops/1stafrica-middle-east-expert-meeting-and-workshop-on-the-health-impact-of-airborne-dust/presentations.

[18] J. P. Engelbrecht, E. V. McDonald, J. A. Gillies, and A. W. Gertler; "Final Report Department of Defense Enhanced Particulate Matter Surveillance Program," Inhalation Toxicology, vol. 21, pp. 297-326, 2009.

[19] N. M. Hamdan, H. Alahawadh, and N. Jisrawi, "Recent Activities at the National X-ray Fluorescence Laboratory (NXFL)," United Arab Emirates IAEA XRF Newsletter Vienna, no. 23, pp. 20-26, 2012.

[20] N. M. Hamdan, N. Jisrawi, H. Al-Awadhi, "Air Pollutants In The Uae: A Study Of Aerosol Particles Using M X-Ray Techiques," in Progress Report of the international Coordinated Research Project (No.1576), International Atomic Energy Agency, Vienna, Austria.

[21] N. M. Hamdan, N. Jisrawi, and H. Al-Awadhi, "Particle Size distribution of Aerosol Pollutants in Dubai," in Proceedings of the International Conference on Environmental Pollution and Remediation, Ottawa, Ontario, Canada, 17-19 August, 2011.

[22] "User Manual Automated Low Volume Aerosol Sampling Devices, Reference Devices PM10 (EN12341) and PM2.5 (EN14907)," Version 4.2, 2014.

[23] K. Slezakova, M. C. Pereira, M. A. Reis, and M. C. Alvim-Ferraz, "Influence of traffic emissions on the composition of atmospheric particles of different sizes-part 1: concentrations and elemental characterization," Journal of Atmospheric Chemistry, vol. 58, no. 1, pp. 55-68, 2007.

[24] X. Querol, M. Viana, A. Alastuey, F. Amato, T. Moreno, S. Castillo, J. Pey, J. De la Rosa, A. Sánchez De La Campa, B. Artíñano, et al., "Source origin of trace elements in pm from regional background, urban and industrial sites of Spain," Atmospheric Environment, vol. 41, no. 34, pp. 7219-7231, 2007. 